\title{
Summertime evolution of snow specific surface area close to the surface on the Antarctic Plateau
}

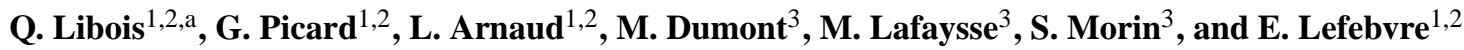 \\ ${ }^{1}$ Univ. Grenoble Alpes, LGGE (UMR5183), 38041 Grenoble, France \\ ${ }^{2}$ CNRS, LGGE (UMR5183), 38041 Grenoble, France \\ ${ }^{3}$ Météo-France - CNRS, CNRM - GAME (UMR 3589), Centre d'Études de la Neige, Grenoble, France \\ a now at: ESCER Centre, Department of Earth and Atmospheric Sciences, Université du Québec à Montréal, \\ 201 Av. du Président-Kennedy, Montréal, H3C3P8, Canada
}

Correspondence to: Q. Libois (libois.quentin@uqam.ca)

Received: 15 July 2015 - Published in The Cryosphere Discuss.: 26 August 2015

Revised: 27 November 2015 - Accepted: 2 December 2015 - Published: 15 December 2015

\begin{abstract}
On the Antarctic Plateau, snow specific surface area (SSA) close to the surface shows complex variations at daily to seasonal scales which affect the surface albedo and in turn the surface energy budget of the ice sheet. While snow metamorphism, precipitation and strong wind events are known to drive SSA variations, usually in opposite ways, their relative contributions remain unclear. Here, a comprehensive set of SSA observations at Dome $\mathrm{C}$ is analysed with respect to meteorological conditions to assess the respective roles of these factors. The results show an average 2-to-3-fold SSA decrease from October to February in the topmost $10 \mathrm{~cm}$ in response to the increase of air temperature and absorption of solar radiation in the snowpack during spring and summer. Surface SSA is also characterized by significant daily to weekly variations due to the deposition of small crystals with SSA up to $100 \mathrm{~m}^{2} \mathrm{~kg}^{-1}$ onto the surface during snowfall and blowing snow events. To complement these field observations, the detailed snowpack model Crocus is used to simulate SSA, with the intent to further investigate the previously found correlation between interannual variability of summer SSA decrease and summer precipitation amount. To this end, some Crocus parameterizations have been adapted to Dome $\mathrm{C}$ conditions, and the model was forced by ERAInterim reanalysis. It successfully matches the observations at daily to seasonal timescales, except for the few cases when snowfalls are not captured by the reanalysis. On the contrary, the interannual variability of summer SSA decrease is poorly simulated when compared to 14 years of microwave satellite data sensitive to the near-surface SSA. A simulation with dis-
\end{abstract}

abled summer precipitation confirms the weak influence in the model of the precipitation on metamorphism, with only $6 \%$ enhancement. However, we found that disabling strong wind events in the model is sufficient to reconciliate the simulations with the observations. This suggests that Crocus reproduces well the contributions of metamorphism and precipitation on surface SSA, but snow compaction by the wind might be overestimated in the model.

\section{Introduction}

The surface energy budget of the Antarctic Plateau depends on snow physical properties (Van As et al., 2005; Brun et al., 2011). Snow specific surface area (the surface area of the iceair interface per unit mass of snow, hereafter referred as SSA) strongly affects snow albedo and light $e$-folding depth, especially in the near-infrared (NIR; e.g. Domine et al., 2006), and thus controls the amount of solar radiation absorbed by the surface (e.g. Warren, 1982; Gardner and Sharp, 2010; Carmagnola et al., 2013). Snow density controls the light $e$-folding depth (Libois et al., 2013) and the effective thermal conductivity of the snowpack (Sturm et al., 1997; Löwe et al., 2013), among other factors. Although the surface of the Antarctic Plateau has often been considered homogeneous in space and stable in time, especially for the calibration of satellite radiometers (e.g. Loeb, 1997; Six et al., 2004), recent studies pointed out that it is subject to large and rapid variations (e.g. Bindschadler et al., 2005; Lacroix et al., 
2009; Champollion et al., 2013). Snow properties evolve over time in response to internal thermodynamical processes such as snow metamorphism (Colbeck, 1983) and densification (Gallée et al., 2001). The surface is also affected by meteorological events such as snowfall and wind events (Kuhn et al., 1977; Champollion et al., 2013). The resulting dependence between snow physical properties and the energy budget of the snowpack gives rise to feedbacks (e.g. Albert et al., 2004) and is therefore of great interest to climate studies. This highlights the need to identify the main processes which drive surface snow evolution on the Antarctic Plateau.

The Plateau is characterized by very low temperatures (annual average around $-50^{\circ} \mathrm{C}$; Augustin et al., 2004), low precipitable water vapour content (less than $1 \mathrm{~mm}$; Tremblin et al., 2011) and low annual accumulation (less than $30 \mathrm{~kg} \mathrm{~m}^{-2}$; Frezzotti et al., 2004), so that the physical processes controlling snow characteristics are substantially different from other environments (e.g. Alps, tundra). During the polar night, temperatures usually remain well below $-50^{\circ} \mathrm{C}$ and snow metamorphism barely operates (Town et al., 2008). On the contrary, at the end of spring, the increase of snow temperature causes significant metamorphism, which leads to an overall decrease of snow SSA (e.g. Picard et al., 2012), densification (Fujita et al., 2009) and other morphological changes of the surface snow (Gow, 1965). As a result, albedo decreases by several percents (Jin et al., 2008; Wang and Zender, 2011), which significantly alters the surface energy budget of the snowpack (van den Broeke, 2004). Picard et al. (2012) have shown that this interdependence between snow optical properties and SSA accelerates snow metamorphism through a positive feedback: when solar energy is absorbed deeper, it warms up the snowpack and increases temperature gradients, which in turn enhances metamorphism close to the surface. As a consequence, SSA generally decreases and $e$-folding depth increases. This positive feedback involving the $e$-folding depth adds up to the snow albedo feedback (e.g. Flanner and Zender, 2006; Box et al., 2012), making summer metamorphism very sensitive to snow optical properties at the surface.

Hitherto, this summertime SSA decrease has been generally deduced from albedo measurements (Jin et al., 2008; Kuipers Munneke et al., 2008), which also depend on illumination conditions, cloudiness and surface roughness (Wang and Zender, 2011), but such a decrease has seldom been measured directly in the field. In addition, the interannual variability of summer metamorphism is poorly understood. Picard et al. (2012) showed a strong correlation with summer amount of precipitation and hypothesized a strong inhibition of the above mentioned positive feedbacks. They used a simple snow evolution model to support their hypothesis, but these features of the seasonal cycle of SSA have never been simulated with a more detailed snowpack model such as Crocus (Brun et al., 1989, 1992). In fact, such models are usually not fully adequate to polar environments (Dang et al., 1997; Groot Zwaaftink et al., 2013). Their semi-empirical param- eterizations for e.g. snow metamorphism, compaction and fresh snow characteristics are indeed often based on observations made in alpine environments (e.g. Marbouty, 1980; Guyomarc'h et al., 1998) and do not necessarily perform well in colder an drier areas. In addition, the few studies dedicated to the simulation of snow physical properties on the Antarctic Plateau focus on the evolution of the snowpack internal and surface temperatures (e.g. Brun et al., 2011; Fréville et al., 2014) or on punctual profiles (Dang et al., 1997; Groot Zwaaftink et al., 2013), rather than on temporal evolution of snow properties. Nevertheless, correctly simulating SSA evolution remains crucial to better understand the sensitivity of this region to future changes in precipitation and air temperature (Krinner et al., 2006).

The aim of this paper is to investigate the summertime evolution of snow SSA at Dome C, as well as to further understand its variability, from the daily to the interannual scale. To quantify this evolution, we use three data sets. Firstly, a large number of in situ SSA measurements were collected at Dome $\mathrm{C}$ during summer campaigns (Sect. 2.1). These included vertical profiles between the surface and $10 \mathrm{~cm}$, and snow samples from the surface, both measured manually during the summer campaigns 2012-2013 and 2013-2014 using the SSA profiler ASSSAP (a light version of POSSSUM; Arnaud et al., 2011). In addition, automatic measurements of snow spectral albedo were used to estimate the evolution of SSA close to the surface during daylight periods. Secondly, the evolution of SSA in the topmost centimetres was estimated from remote sensing observations of the snowpack in the microwave range over the period 2000-2014 based on Picard et al. (2012) (Sect. 2.2). Thirdly, the detailed snowpack model SURFEX/ISBA-Crocus (hereinafter referred as Crocus; Vionnet et al., 2012) was used to simulate snow SSA at Dome C (Sect. 2.3). For this, it was adapted to Dome C conditions by changing some parameterizations (Libois et al., 2014a) and forced by ERA-Interim near-surface reanalysis (Dee et al., 2011). The observations and simulations are compared in Sect. 3. The interannual variability of summer metamorphism is eventually investigated in more details with Crocus. In particular, the sensitivity of simulated SSA to changes in precipitation, wind and temperature are estimated, which also helps identifying the current potential and limits of Crocus (Sect. 4).

\section{Materials and methods}

The temporal variations of snow SSA at Dome C were estimated from in situ measurements and satellite data. Snow spectral albedo in the visible and NIR range has been measured using a specifically designed automatic instrument, from which surface SSA variations were deduced over the summers 2012-2013 and 2013-2014. To complement these automatic measurements and to explore the variations deeper in the snowpack, supplementary SSA measurements were 
taken manually with the instrument ASSSAP. These comprised surface SSA measurements, as well as vertical profiles down to $10 \mathrm{~cm}$ depth. Eventually, to study the interannual variations of surface SSA, satellite measurements of microwave brightness temperature were used.

\subsection{Field observations}

\subsubsection{SSA estimation from spectral albedo measurements}

Using the dependence between snow albedo and SSA close to the surface (Warren, 1982; Domine et al., 2006), variations of the latter were estimated from spectral albedo measurements in the range $300-1100 \mathrm{~nm}$ ( $3 \mathrm{~nm}$ resolution). Albedo was recorded every $12 \mathrm{~min}$ at approximately $600 \mathrm{~m}$ west of Concordia station $\left(75.1^{\circ} \mathrm{S}, 123.3^{\circ} \mathrm{E} ; 3230 \mathrm{ma}\right.$ a.s.1.), in the "clean area" $\left(75.09960^{\circ} \mathrm{S}, 123.30244^{\circ} \mathrm{E}\right)$. The albedometer, designed and assembled at Laboratoire de Glaciologie et Géophysique de l'Environnement, was deployed on 10 December 2012 and has been running almost continuously since then. It has two similar measurement heads looking to the surface and to the sky (Fig. 1). The horizontality of the heads was checked at installation with an electronic inclinometer and was better than $0.5^{\circ}$. One head is optimized for measurements in the UV and visible, the other for visible and NIR. Only the data from the visible-NIR head were used in the present study. Each measurement head consists of one upward- and one downward-looking fiber optic mounted with specially designed cosine collectors with a $180^{\circ}$ field of view. The fibers are sequentially connected to an Ocean Optics ${ }^{\circledR}$ Maya Pro spectrophotometer through a Leoni ${ }^{\circledR}$ optical multiplexer. The spectral albedo is obtained by computing the ratio of upwelling to downwelling irradiance after calibration of the raw measurements. We developed an algorithm to estimate the time series of snow SSA from these measurements. Its steps are computed as follows.

1. Albedo correction. Downwelling hemispherical irradiance measurements are strongly affected by the quality of the cosine response of the light collector, especially at high solar zenith angles (SZA) typical of the Antarctic Plateau (e.g. van den Broeke, 2004). Despite our effort to build highly diffusing collectors, small remaining deviations from the ideal cosine response need to be corrected. To this end, the angular response of our collectors was determined in the laboratory and used to estimate the true incident and reflected fluxes from the measured ones (Grenfell et al., 1994). The deviation from the perfect cosine response is less than $4 \%$ for angles below $70^{\circ}$ but increases beyond $80^{\circ}$ due to the dome geometry of our collectors that capture a significant amount of light at grazing angles (e.g. Bernhard et al., 1997). In addition, the correction requires knowledge of the direct vs. diffuse parts of the incident flux (Grenfell et al., 1994). Since this information is not available from measurements, the direct/diffuse ratio was supposed to depend only on SZA and was thus treated in the same way for clear-sky and cloudy conditions. It was calculated at all wavelengths with the atmospheric radiative transfer model SBDART (Ricchiazzi et al., 1998) for typical summer clear-sky conditions at Dome C. Contrary to incident radiation, reflected radiation is assumed isotropic. Although the upward- and downward-looking fibers are assumed to have the same angular response, the transmittances of both optical lines are different. To account for this effect, both lines were intercalibrated. For this, the two collectors were consecutively set in the downward-looking position by simply flipping vertically the fibers of $180^{\circ}$. The procedure lasted less than $30 \mathrm{~s}$ and was performed on a clear-sky day, so that the upward flux could be assumed constant. The ratio of both spectra was used to rescale all the albedos analysed in this study. Despite all these precautions, albedo values sometimes exceed 1.0 in the visible range at high SZA and occasionally reach up to 1.05 , indicating insufficient correction.

2. Daily computation of albedo. To minimize the effect described above, we consider only albedo at noon. For this, the five measurements taken between 11:30 and 12:30 LT are averaged every day. This means that albedo measurements are taken at constant solar azimuth angle throughout the summer but not necessarily at constant SZA. This choice is also made because preferential orientation of surface relief is known to translate into an azimuthal dependence of albedo (Wang and Zender, 2011), an artefact that should be avoided here. We nevertheless tried to use constant SZA (i.e. variable local hour and azimuth) which minimizes errors due to imperfect cosine response of the collectors, and the results were very similar (less than $15 \%$ difference).

3. Daily SSA estimation. The SSA of surface snow is then estimated from the daily albedo spectral dependence. To this end, the snowpack is assumed semi-infinite and uniform. In this case, the diffuse and direct spectral albedos $\alpha_{\lambda}^{\text {diff }}$ and $\alpha_{\lambda}^{\text {dir }}$ are related to SSA using the analytical formulation of Negi et al. (2011):

$$
\begin{aligned}
& \alpha_{\lambda}^{\text {diff }}=\exp \left(-4 \sqrt{\frac{2 B \gamma_{\lambda}}{3 \rho_{\text {ice }} \operatorname{SSA}(1-g)}}\right) \\
& \alpha_{\lambda}^{\operatorname{dir}}(\mu)=\exp \left(-\frac{12}{7}(1+2 \mu) \sqrt{\frac{2 B \gamma_{\lambda}}{3 \rho_{\text {ice }} \operatorname{SSA}(1-g)}}\right)
\end{aligned}
$$

where $\mu=\cos (\theta), \theta$ is the SZA, $B$ and $g$ describe snow single scattering properties and are assumed constant ( $B=1.6$ and $g=0.86$ after Libois et al., 2014b), $\rho_{\text {ice }}=917 \mathrm{~kg} \mathrm{~m}^{-3}$ is the bulk density of ice at $0^{\circ} \mathrm{C}$, and $\gamma_{\lambda}$ is the wavelength-dependent absorption coefficient 


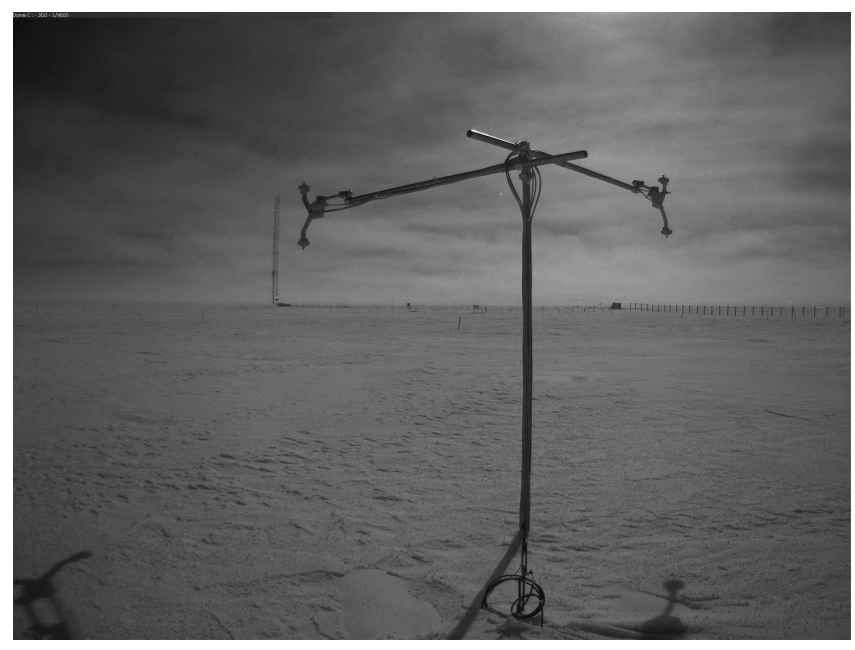

Figure 1. Spectral albedo measurement at Dome C (picture taken on 12 January 2014, 11:00 LT). The vertical mast is approximately $2 \mathrm{~m}$ high.

of ice, taken from Warren and Brandt (2008). SSA is retrieved by minimizing the root mean square deviation between the spectra of daily albedo and the theoretical albedo, accounting for the direct and diffuse components of solar irradiance calculated with SBDART. The comparison is computed in the range 700-1050 nm where the impact of light-absorbing impurities is minor (Warren and Wiscombe, 1980) and the sensitivity of snow albedo to snow SSA is high. To account for remaining uncertainties in the albedo spectra, a scaling coefficient $A$ is optimized along with SSA, so that the function to optimize $\alpha$ is actually given by

$\alpha_{\lambda}=A\left[r_{\lambda}^{\mathrm{diff}} \alpha_{\lambda}^{\mathrm{diff}}(\mathrm{SSA})+\left(1-r_{\lambda}^{\mathrm{diff}}\right) \alpha_{\lambda}^{\mathrm{dir}}(\mathrm{SSA})\right]$,

where $r_{\lambda}^{\text {diff }}$ gives the proportion of diffuse light. $A$ is meant to compensate for all the factors affecting albedo measurements in a wavelength-independent way which were not explicitly corrected by the previous processing steps. This inversion method is somehow similar to estimating SSA from albedo ratios at different wavelengths (Zege et al., 2008).

4. SSA evolution through the summer. This procedure is applied every day independently of sky conditions. It is repeated every year from 18 October to 27 February, when SZA at noon remains lower than $67^{\circ}$. Out of this period, we consider that albedo measurements are not accurate enough to retrieve SSA (e.g. Wang and Zender, 2011)

The SSA retrieved with this algorithm roughly corresponds to the SSA of the top 1-2 cm of the snowpack since the light $e$-folding depth ranges from approximately $5 \mathrm{~mm}$ at
$1050 \mathrm{~nm}$ to $4 \mathrm{~cm}$ at $700 \mathrm{~nm}$ depending on snow characteristics (Libois et al., 2013). A rigorous forward estimation of the accuracy of the algorithm would require a thorough analysis of several factors including the uncertainty on the collector calibration procedure, the effect of snow anisotropy (Carmagnola et al., 2013), the shadowing of the surface by the instrument, the potential tilt of the sensor, the validity of the semi-infinite snowpack assumption, etc. Taking into account all these factors and their intercorrelation is beyond the scope of this article and will be addressed in future work. Here the accuracy is estimated using a global approach based on the analysis of the coefficient $A$ obtained during the retrieval. Over the period of observations, it varied in the range 0.98 1.03 , while ideal measurements would have yielded $A=1$. The deviation of $A$ from 1 , that is -2 to $+3 \%$, gives an estimation of the albedo measurement accuracy. Hence we assume that the albedo accuracy is $3 \%$. The corresponding accuracy on SSA estimation is then derived from Eq. (1). For the spectral range of interest and the SSA values encountered at Dome C, the estimated accuracy of the SSA retrieval is better than $25 \%$.

\subsubsection{Surface SSA}

The SSA of surface snow was also manually measured during the summer campaigns 2012-2013 and 2013-2014. In 2012-2013, surface SSA was measured using ASSSAP in horizontal position. For this, ASSSAP slides along a $1 \mathrm{~m}$ long horizontal rail fixed approximately $5 \mathrm{~cm}$ above the surface and measures the snow reflectance at $1310 \mathrm{~nm}$ (Fig. 2), from which the surface SSA is estimated with an accuracy of $10-15 \%$ using the algorithm described in Arnaud et al. (2011). Every 2 days from 22 November 2012 to 16 January 2013 (except from 3 to 6 January), $1 \mathrm{~m}$ long horizontal transects of SSA were thus measured without disturbing the snow surface, at two fixed locations distant of about $5 \mathrm{~m}$ situated $500 \mathrm{~m}$ south-east of the station $\left(75.10374^{\circ} \mathrm{S}\right.$, $123.34093^{\circ} \mathrm{E}$ ). During this summer campaign, the SSA of precipitation particles was also measured at several occasions using ASSSAP sampler. For this, freshly deposited particles were collected on a metallic plate and gathered to fill the sampler. From 27 November 2013 to 29 January 2014, the SSA of snow samples taken from the surface were measured almost every day using ASSSAP sampler. These measurements were taken $100 \mathrm{~m}$ further east compared to the previous year $\left(75.10379^{\circ} \mathrm{S}, 123.34484^{\circ} \mathrm{E}\right)$ and amounted to a total of 630 snow samples taken randomly in an area of approximately $1000 \mathrm{~m}^{2}$ over 64 days. As light $e$-folding depth at $1310 \mathrm{~nm}(\sim 2 \mathrm{~mm})$ is smaller than in the range $700-1050 \mathrm{~nm}$, the SSA measured with ASSSAP are not directly comparable to the albedo-derived estimates given that the snow is rarely homogeneous near the surface. 


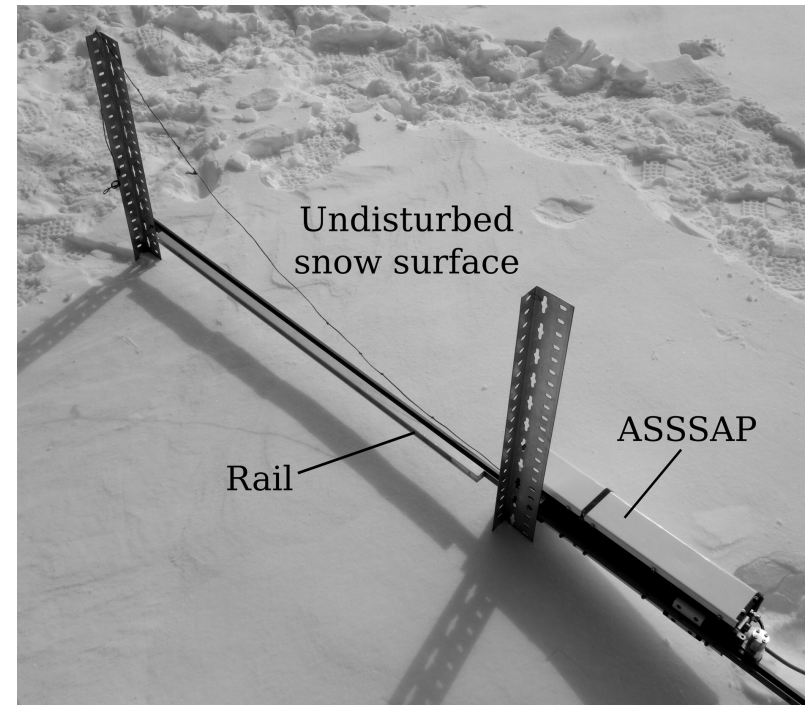

Figure 2. Experimental setup for transect measurements of SSA using ASSSAP in horizontal position. The distance between both vertical stakes is $1 \mathrm{~m}$. ASSSAP slides along the horizontal rail and records the SSA of the surface beneath every $10 \mathrm{~ms}$. For the measurements, the setup was covered by a dark tarpaulin to avoid the supersaturation of ASSSAP photodiodes.

\subsubsection{Profiles of SSA}

From 23 November 2012 to 16 January 2013, 98 vertical profiles of SSA were measured with ASSSAP from the surface to $10 \mathrm{~cm}$ depth at $1 \mathrm{~cm}$ resolution (e.g. Carmagnola et al., 2014). The measurements were performed at two different sites. The first one was $600 \mathrm{~m}$ west of the main building of Concordia station $\left(75.09971^{\circ} \mathrm{S}, 123.30224^{\circ} \mathrm{E}\right)$ and the second one was $500 \mathrm{~m}$ south-east of the station, just beside the location of the surface SSA measurements. Every day during this period (except from 3 to 6 January), two profiles were measured, one day at the first site, the other day at the second one. All these profiles were taken at different places in undisturbed snow areas with a minimum distance of $5 \mathrm{~m}$ between each other. From 25 November 2013 to 25 January 2014, one vertical profile of SSA was measured with ASSSAP every 2 days, amounting to 32 profiles taken in the same area where surface snow samples were taken.

\subsection{Satellite observations}

The SSA time series from 1999 to present was estimated from high-frequency microwave radiometers using the approach proposed in Picard et al. (2012). The advantage of observing in the microwave domain is the independence to weather conditions and illumination, which allows to retrieve SSA year-round even during the polar night. To obtain information on the surface snow, we used observations from the Advanced Microwave Sounding Unit (AMSU) constellation that is able to operate up to $150 \mathrm{GHz}$. Using observations at
150 and $89 \mathrm{GHz}$ makes it possible to estimate the average SSA over the top $7 \mathrm{~cm}$ approximately. Lower frequencies are more sensitive to snow properties deeper down in the snowpack (Surdyk, 2002; Picard et al., 2009) and present a lower interest for this study.

Following the method of Picard et al. (2012), the DMRTML forward microwave emission model (Picard et al., 2013) is used to compute the microwave brightness temperature of an idealized two-layer snowpack. The top layer is $7 \mathrm{~cm}$ thick and the bottom one is semi-infinite. The temperature of both layers is set to the 10-day average air temperature taken from ERA-Interim and the density is assumed constant at $320 \mathrm{~kg} \mathrm{~m}^{-3}$ according to the mean surface density reported by Libois et al. (2014a). The SSA in both layers are the unknowns to be estimated. For this, for each 10-day period from 1999 to present, the SSA in both layers is optimized so that the model predictions at 150 and $89 \mathrm{GHz}$ match the satellite observations. To relate the SSA to the grain size metric $r$ required by the DMRT theory, an empirical scaling coefficient is used according to Brucker et al. (2010), such that $\mathrm{SSA}=3 /\left(\rho_{\text {ice }} \frac{r}{2.8}\right)$.

This method is simple because using two observations it considers only two unknowns, while the density and layer thickness are probably variable and are known to affect microwave signal as well (even if this effect is of second order compared to the SSA). As a result, this SSA time series is not expected to be as accurate as the spectrometry-based approach described in Sect. 2.1.1. The most critical assumption is probably that of constant density. Assuming a density of $300 \mathrm{~kg} \mathrm{~m}^{-3}$ (respectively $350 \mathrm{~kg} \mathrm{~m}^{-3}$ ) instead of $320 \mathrm{~kg} \mathrm{~m}^{-3}$ yields SSA differences up to $+20 \%$ (respectively $-40 \%$ ), which gives a broad estimate of $40 \%$ for the accuracy of the method. Nevertheless, with 14 years of data there is a good indication of the interannual variability of the seasonal variations of SSA.

\subsection{Crocus simulations}

\subsubsection{Reference simulation (A)}

The temporal evolution of snow physical properties at Dome $\mathrm{C}$ was computed with the detailed snowpack model Crocus (Vionnet et al., 2012), which simulates the evolution of a one-dimensional multi-layer snowpack in response to meteorological conditions. The number and thickness of numerical snow layers evolve with time. The snow prognostic properties relevant for this study are snow SSA, snow density, snow temperature and snow sphericity (Carmagnola et al., 2014). Crocus was adapted to the specific meteorological conditions prevailing at Dome $\mathrm{C}$, essentially to handle the very low amount of precipitation, the characteristics of fresh snow, the compaction of snow by the wind during drift events and the rate of metamorphism. In particular, the optimal thicknesses of the five topmost layers were set at 2, 3, 5, 5 and $10 \mathrm{~mm}$, to ensure that surface processes are accurately 
represented. The fresh snow density is fixed at $170 \mathrm{~kg} \mathrm{~m}^{-3}$ and fresh snow SSA is fixed at $100 \mathrm{~m}^{2} \mathrm{~kg}^{-1}$. All these adaptations are detailed in Libois et al. (2014a). For the present study, a few more modifications were made.

- In Crocus the impact of drift (Vionnet et al., 2012) was originally given in terms of changes in snow dendricity and sphericity (Brun et al., 1992). It was reformulated in terms of SSA using Eq. (5) of Carmagnola et al. (2014), which is valid for SSA less than $65 \mathrm{~m}^{2} \mathrm{~kg}^{-1}$. In case of higher SSA as encountered at Dome $\mathrm{C}$, this formulation leads to SSA decrease during wind drift events. Since such decrease is contradictory to observations in Antarctica (Kuhn et al., 1977; Grenfell et al., 1994), when the parameterization predicts a decrease of SSA, the latter is actually forced to remain unchanged.

- SSA decrease is computed from the formulation F06 of snow metamorphism (Carmagnola et al., 2014) which is based on a fit of the semi-empirical microphysical model of SSA decrease rate proposed by Flanner and Zender (2006). Because of working in the mid-latitude context, the fit in Carmagnola et al. (2014) was computed over a period of 14 days, as in Oleson et al. (2010). Here we use the same approach but extend the period to 100 days to account for the slower metamorphism resulting from the low temperatures prevailing at Dome C. Moreover, below $-50^{\circ} \mathrm{C}$, where the parameterization is no more valid, we implemented a scaling of the temperature dependence of snow metamorphism based on Clausius-Clapeyron law for vapour saturation pressure. This latter choice has little impact because at such low temperatures snow metamorphism is anyway negligible.

- The vertical profiles of absorbed solar energy were computed with the physically based radiative transfer model TARTES (Libois et al., 2013) at $10 \mathrm{~nm}$ spectral resolution rather than with the original semi-empirical parameterization implemented in Crocus (Brun et al., 1992). Indeed, TARTES has been fully implemented in Crocus and is used to compute the vertical profile of energy absorption of a multi-layered snowpack based on density and SSA profiles. TARTES also accounts explicitly for snow grain shape, through the asymmetry factor $g$ and the absorption enhancement parameter $B$. According to Libois et al. (2014b), we chose $B=1.6$ and $g=0.86$. TARTES simulates the impact of light-absorbing impurities in snow. Here a constant load of black carbon equal to $3 \mathrm{ng} \mathrm{g}^{-1}$ was assumed, in agreement with observations (Warren et al., 2006).

- Although in Crocus the roughness length for momentum is usually 10 times larger than that for heat transfer at the air-snow interface, here both were fixed to $1 \mathrm{~mm}$, as Brun et al. (2011) did in a previous study because this choice produced the best fit between simulated and observed surface temperatures at Dome C.

Crocus was forced by ERA-Interim atmospheric reanalysis for $2 \mathrm{~m}$ air temperature and specific humidity, surface pressure, precipitation amount, $10 \mathrm{~m}$ wind speed and downward radiative fluxes. ERA-Interim data were already used by Fréville et al. (2014) to simulate snow surface temperature on the Antarctic Plateau. As detailed in Libois et al. (2014a), precipitation rate was multiplied by 1.5 to ensure that simulated annual snow accumulation matches observations at Dome C. On the contrary, ERA-Interim wind was found in good agreement with measurements performed on the $40 \mathrm{~m}$ high instrumented tower at Dome C (Genthon et al., 2013). Libois et al. (2014a) also pointed out that drift events observed at Dome $\mathrm{C}$ could satisfactorily be predicted from ERA-Interim wind time series, further supporting the consistency of wind data. As for $2 \mathrm{~m}$ air temperature, it does not show any significant bias during the summer from 2000 to 2013 compared to automatic weather station Dome C II (http://amrc.ssec.wisc.edu/aws). It does show a positive bias of about $2 \mathrm{~K}$ during the winter, but this is not critical for our study because snow metamorphism barely operates in winter.

The snowpack was first initialized with a depth of $12 \mathrm{~m}$ using observations of density and SSA at Dome C (Picard et al., 2014). It comprised 25 layers. Crocus was then run three times consecutively for the period 2000-2010, which ensured that snow characteristics in the top $2 \mathrm{~m}$ of the snowpack were consistently initialized. Then, Crocus was run from 2000 to 2014 and the full state of the snowpack was recorded every $12 \mathrm{~h}$, yielding the reference simulation A that is analysed in the following. The discontinuity in the spinup is not critical here since the analysis focuses with priority to the end of the period.

\subsubsection{Supplementary simulations $(\mathrm{B}, \mathrm{C}, \mathrm{D}, \mathrm{E})$}

To estimate the sensitivity of Crocus simulations to summer precipitation and air temperature and to test the hypotheses proposed by Picard et al. (2012) to explain the intensity and interannual variability of summer metamorphism at Dome C, four additional Crocus simulations were performed and are summarized in Table 1. In simulation B, precipitation is disabled throughout the summer (November-February). In simulation $\mathrm{C}, 2 \mathrm{~m}$ air temperature is increased by $3 \mathrm{~K}$ throughout the year to mimic the average warming predicted by the CMIP5 ensemble on the Antarctic Plateau by 2100 for the RCP4.5 scenario (van Oldenborgh et al., 2013). To estimate the strength of the positive feedback between snow albedo and snow metamorphism, in simulation D the snow optical properties are calculated assuming the SSA remains constant, equal to $100 \mathrm{~m}^{2} \mathrm{~kg}^{-1}$. To isolate the impact of precipitation on summer metamorphism interannual variability from that of snow drift which increases snow density and thus decreases snow metamorphism (Flanner and Zender, 2006), in simulation $\mathrm{E}$ the $10 \mathrm{~m}$ wind speed forcing was taken constant 
Table 1. Crocus simulations performed for this study.

\begin{tabular}{ll}
\hline Simulation & Characteristics \\
\hline A & Reference \\
B & Same as A; precipitation set to 0 from November to February \\
C & Same as A; 2 m air temperature increased by $3 \mathrm{~K}$ \\
D & Same as A; SSA kept constant at $100 \mathrm{~m}^{2} \mathrm{~kg}^{-1}$ for calculations of optical properties \\
E & Same as A; wind speed in the forcing is constant, \\
& equal to the average ERA-Interim wind speed over the simulation period $\left(5 \mathrm{~m} \mathrm{~s}^{-1}\right)$, \\
& fresh snow density is set to $270 \mathrm{~kg} \mathrm{~m}^{-3}$ \\
\hline
\end{tabular}

- equal to its mean annual value - throughout the simulation. In this simulation, the density for fresh snow was also increased from the nominal value of 170 to $270 \mathrm{~kg} \mathrm{~m}^{-3}$ to compensate the fact that averaged wind speed is not sufficient to increase snow density through snow drift. This choice ensured that simulated vertical profiles of density remained consistent with the observations.

\section{Results}

Simulations and measurements show that SSA close to the surface evolves at different timescales. The SSA of the top millimetres is essentially driven by meteorological conditions such as snowfall and drift events (e.g. Grenfell et al., 1994), leading to rapid variations at the daily scale. Deeper, a seasonal decreasing trend is superimposed to these rapid variations. This decrease extends from late October to early February and is highly variable from one year to another. The following sections address these two timescales.

\subsection{Seasonal variations of SSA in the uppermost $2 \mathrm{~mm}$}

For each $1 \mathrm{~m}$ long horizontal transect taken with ASSSAP in 2012-2013, the average surface SSA in the range 0.25$0.75 \mathrm{~m}$ was computed. For that, the measured transect was first divided in $1 \mathrm{~cm}$ intervals over which the median SSA value was taken. These medians were then used to compute the average value and standard deviation for the transect, from which the temporal evolution of SSA at the two locations was deduced (Fig. 3a). The main features are the same for both sites, with SSA ranging from about 25 to $90 \mathrm{~m}^{2} \mathrm{~kg}^{-1}$. The periods when precipitation or diamond dust were visually observed at Dome $\mathrm{C}$ are also indicated. It highlights that most rapid SSA increases followed precipitation and diamond dust events, as expected because such events bring at the surface snow particles characterized by high SSA as pointed out by Walden et al. (2003) and confirmed by our SSA measurements of precipitation particles that ranged from 90 to $120 \mathrm{~m}^{2} \mathrm{~kg}^{-1}$. SSA generally decreased after fresh snow deposition due to metamorphism (e.g. Taillandier et al., 2007), and it took about 10 days for SSA to drop from approximately 90 to $30 \mathrm{~m}^{2} \mathrm{~kg}^{-1}$. More rapid decreases were observed, like on 14 December 2012, after a strong wind event blew away a thin layer of soft and high SSA snow and left hard windpacked old snow with low SSA. Erosion rather than snow metamorphism thus explains such rapid changes. The slight continuous increase in SSA observed from 10 to 16 January 2013 is concomitant with the formation of hoar crystals at the surface as reported by Gow (1965) and Champollion et al. (2013). The formation of such crystals may thus contribute to increase snow SSA at the surface (Domine et al., 2009; Gallet et al., 2013).

Figure $3 \mathrm{~b}$ shows the time series of surface SSA obtained from the snow samples measured during summer 20132014. The SSA of individual samples was in the range 28$185 \mathrm{~m}^{2} \mathrm{~kg}^{-1}$ and the daily median SSA was in the range 35$85 \mathrm{~m}^{2} \mathrm{~kg}^{-1}$. Again, the largest SSA increases occurred after precipitation events. These were followed by periods with SSA decrease. Significant variations also occurred during periods without observed precipitation (e.g. 15-28 December 2013). Snow drift was regularly observed during these periods. The large standard deviation of measurements taken the same day highlights the spatial variability of surface SSA, mainly resulting from snow drift (Libois et al., 2014a). From 12 to 16 January, hoar crystals covered most of the surface and maintained the SSA around $60 \mathrm{~m}^{2} \mathrm{~kg}^{-1}$ despite the absence of precipitation.

These observed SSA variations, corresponding roughly to the top $2 \mathrm{~mm}$ of the snowpack, were compared to the reference Crocus simulation A. For this, the average SSA of the top $2 \mathrm{~mm}$ was computed from the simulated SSA profiles. The simulated SSA vary in the same range as the measured ones (Fig. 3). In addition, Crocus reproduces relatively well the rapid SSA increases, except when precipitation is not predicted by ERA-Interim (e.g. 1 January 2013 and 2527 January 2014). The rate of decrease of SSA due to metamorphism in between precipitation events is also correctly simulated for summer 2012-2013 but slightly less so for 2013-2014, probably because metamorphism is better captured when an individual snow location is followed throughout the summer, which was the case in 2012-2013 but not in 2013-2014. The effect of soft snow removal by the wind as well as the formation of surface hoar are currently not sim- 

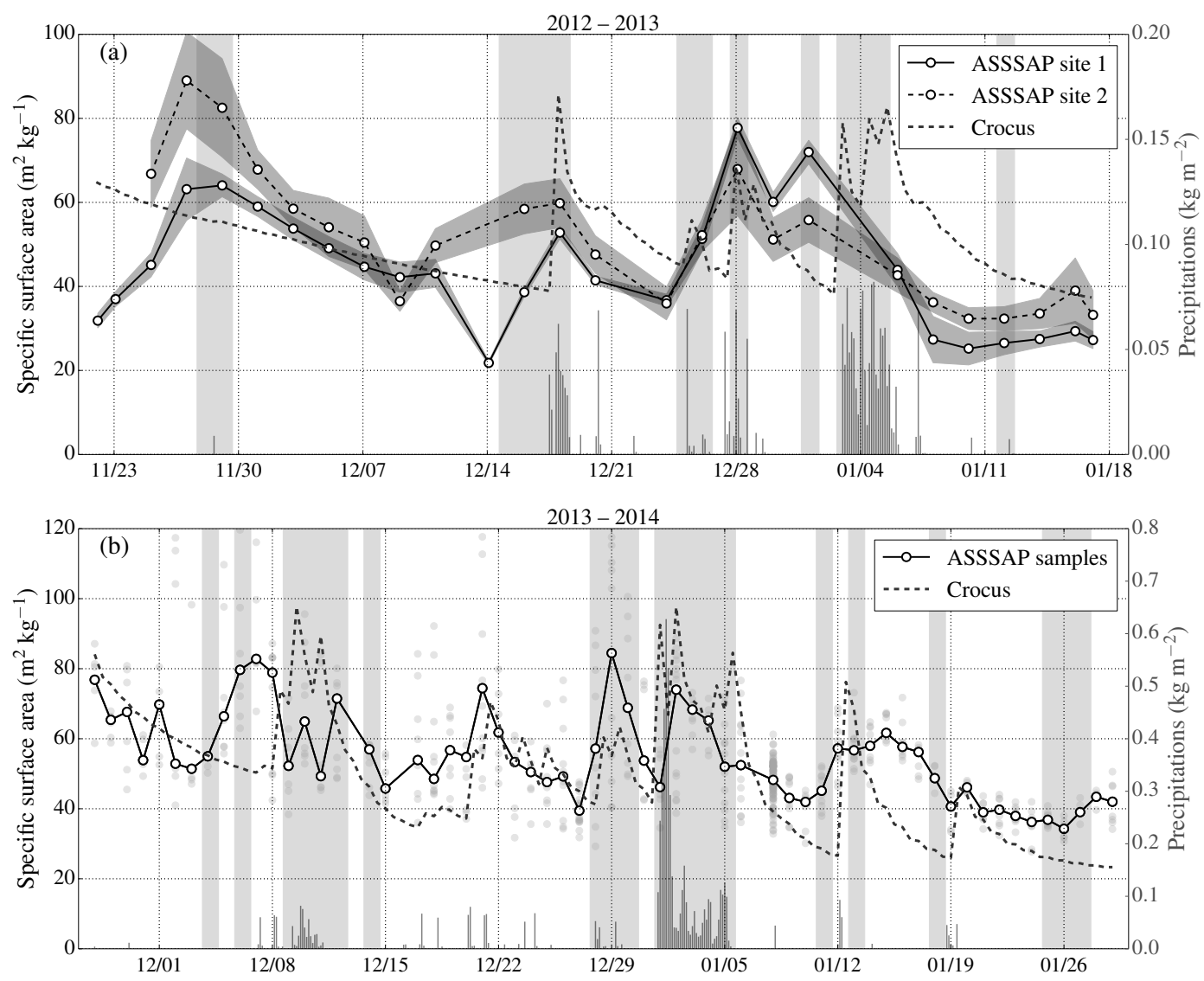

Figure 3. (a) Evolution of surface SSA during summer 2012-2013 deduced from the $1 \mathrm{~m}$ long horizontal transects taken with ASSSAP at 2 distinct locations (ASSSAP site 1 and site 2) and SSA of the top $2 \mathrm{~mm}$ simulated with Crocus. The points show the mean value of each transect and the standard deviation is indicated by the shaded area. (b) Evolution of surface SSA during summer 2013-2014 deduced from the snow samples measured with ASSSAP and SSA of the top $2 \mathrm{~mm}$ simulated with Crocus. The grey circles indicate single measurements and the white circles highlight the median value for each day. In (a and $\mathbf{b})$, the shaded bands indicate the periods of observed snowfall or diamond dust at Dome C. The amount of precipitation predicted by ERA-Interim is also shown (right $y$ axis, dark grey columns).

ulated by Crocus, which explains the discrepancies between model and observations when these processes were observed.

\subsection{Seasonal variations of SSA in the uppermost 2 and $10 \mathrm{~cm}$}

Beyond these rapid variations of surface SSA, mainly due to snow deposition and transport, the spectral albedo measurements and the vertical profiles show that SSA decreases all along the summer. Figure 4 shows the time series of SSA deduced from spectral albedo measurements, which corresponds approximately to the SSA of the top $2 \mathrm{~cm}$ of the snowpack. During summer 2013-2014, the SSA clearly decreased from 80 to $30 \mathrm{~m}^{2} \mathrm{~kg}^{-1}$ from late October to late January, with most of the decrease occurring before December. This seasonal trend is not fully observed in 2012-2013 because the time series begins on 10 December (date of deployment of the instrument), so that only the rapid variations due to snowfall are visible. Both years are characterized by a large and sudden increase of surface SSA at the end of summer, result- ing from a large snowfall (25 February 2013 and 11 February 2014).

The average SSA of the top $2 \mathrm{~cm}$ was computed from the SSA profiles simulated by Crocus. With a mean negative bias of $1.2 \mathrm{~m}^{2} \mathrm{~kg}^{-1}$ and a root mean square difference of $8.1 \mathrm{~m}^{2} \mathrm{~kg}^{-1}$ over the two summers, the simulated values are in very good agreement with the observations (Fig. 4). Moreover, Crocus successfully simulates the seasonal decrease of SSA observed in 2013-2014, as well as the large increase resulting from the large amounts of fresh snow deposited in February 2013 and 2014. The model also captures the rapid variations of SSA due to precipitation, as already mentioned in Sect. 3.1. Since solar irradiance decreases exponentially with depth, the uppermost millimetres of the snowpack contribute more to the albedo than the snow below. As a result, the SSA retrieved from albedo measurements is the result of a convolution of the actual SSA profile by an exponential to a first approximation. To account for this effect, the simulated SSA was also computed using a $2 \mathrm{~cm}$ exponential decay (e.g. 

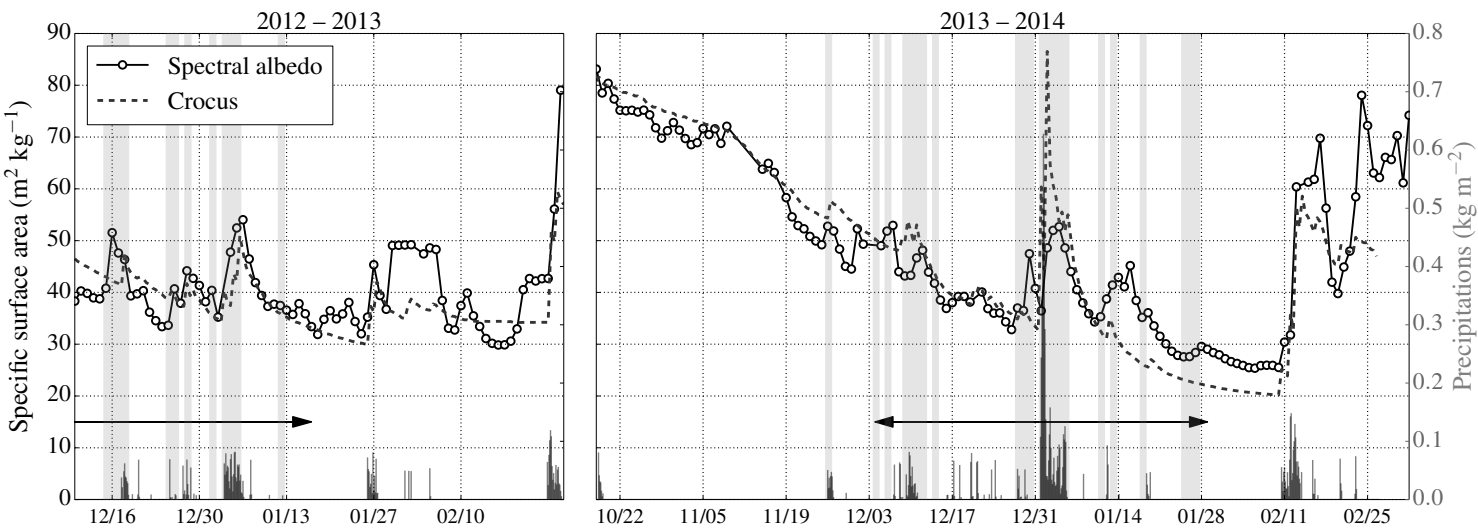

Figure 4. Variations of SSA close to the surface deduced from the spectral albedo measurements, and average SSA of the top $2 \mathrm{~cm}$ of the snowpack simulated with Crocus for the summers 2012-2013 and 2013-2014. The shaded bands indicate the periods of observed snowfall at Dome C. The amount of precipitation predicted by ERA-Interim is also shown (right $y$ axis, dark grey columns). The horizontal arrows highlight the periods of measurements shown in Fig. 3.

Mary et al., 2013) rather than a linear average. This resulted in slightly higher SSA (less than $5 \%$ ). Likewise, since the choice of $2 \mathrm{~cm}$ is to some extent arbitrary, the average was also computed over the topmost 1 and $4 \mathrm{~cm}$. It resulted in less than $5 \%$ changes, except for the simulated SSA spikes following precipitation that were more marked for $1 \mathrm{~cm}$. Hence the simulated seasonal trend remains consistent with the observations however near-surface SSA is defined.

The summertime decrease of SSA is confirmed by the series of vertical profiles of SSA taken independently with ASSSAP during the same two summers (Fig. 5). The average SSA in the top $10 \mathrm{~cm}$ decreased from 45 to $28 \mathrm{~m}^{2} \mathrm{~kg}^{-1}$ in 2012-2013 and from 37 to $29 \mathrm{~m}^{2} \mathrm{~kg}^{-1}$ in $2013-2014$. The summer decrease was thus more significant in 2012-2013 than in 2013-2014, which is reproduced by Crocus (Fig. 5). More precisely, the main difference between both summers is the initial value of SSA. This can be explained by the fact that ERA-Interim precipitation accumulated from March $1^{\text {st }}$ to November $1^{\text {st }}$ was $45 \%$ larger in 2012 than in 2013. The SSA decrease observed in 2013-2014 is successfully simulated, even at low temperatures although Crocus was developed for alpine conditions. In the 2012-2013 simulation Crocus underestimates the rapid SSA decrease measured from mid-December. These two independent sets of measurements nevertheless demonstrate that Crocus forced by ERA-Interim is able to simulate the summer variations of SSA close to the surface.

\subsection{Interannual variability of SSA in the uppermost $10 \mathrm{~cm}$}

In situ measurements of SSA down to $10 \mathrm{~cm}$ depth are only available for the summers 2012-2013 and 2013-2014. To further understand summer metamorphism at Dome $\mathrm{C}$, the time series of simulated SSA was compared to the SSA estimated from AMSU observations from 2000 to 2014 (Fig. 6).
For this, the average SSA of the top $7 \mathrm{~cm}$ was computed daily for the simulated snowpack. It was compared to the SSA estimated from the measured snowpack brightness temperatures (Sect. 2.2).

The SSA simulated with Crocus and that deduced from AMSU observations (Fig. 6) are well correlated $(r=0.70)$, which highlights the ability of Crocus to simulate the annual cycle of surface SSA over more than a decade. The SSA values are also in the same range. In particular, the rapid decrease at the end of spring, as well as the slower rate of increase in winter, are similar in the simulation and observations. The rapid increases occurring around 15 February and already observed in Fig. 4 are generally well reproduced and correspond to strong precipitation events (e.g. 2002, 2004, 2011). In contrast, the amplitude of SSA variations is occasionally very different. For instance, the SSA decrease during the summers 2001-2002 and 2007-2008 is much larger in the model than suggested by satellite observations. Moreover, the simulated SSA increased almost as usual in winters 2007 and 2010 while AMSU data suggest that this increase was much less than usual. AMSU observations nevertheless confirm that summer metamorphism was more intense in 2012-2013 than in 2013-2014, as noted from in situ measurements (Fig. 5).

\section{Discussion}

A version of Crocus adapted to the meteorological conditions of the Antarctic Plateau was used to simulate the temporal variability of snow SSA close to the surface at Dome $C$, in order to identify the physical processes responsible for summertime SSA variations. In general, a satisfactory agreement was obtained with regards to in situ measurements and remote sensing observations of snow SSA, even though some discrepancies remained between model and observations. 

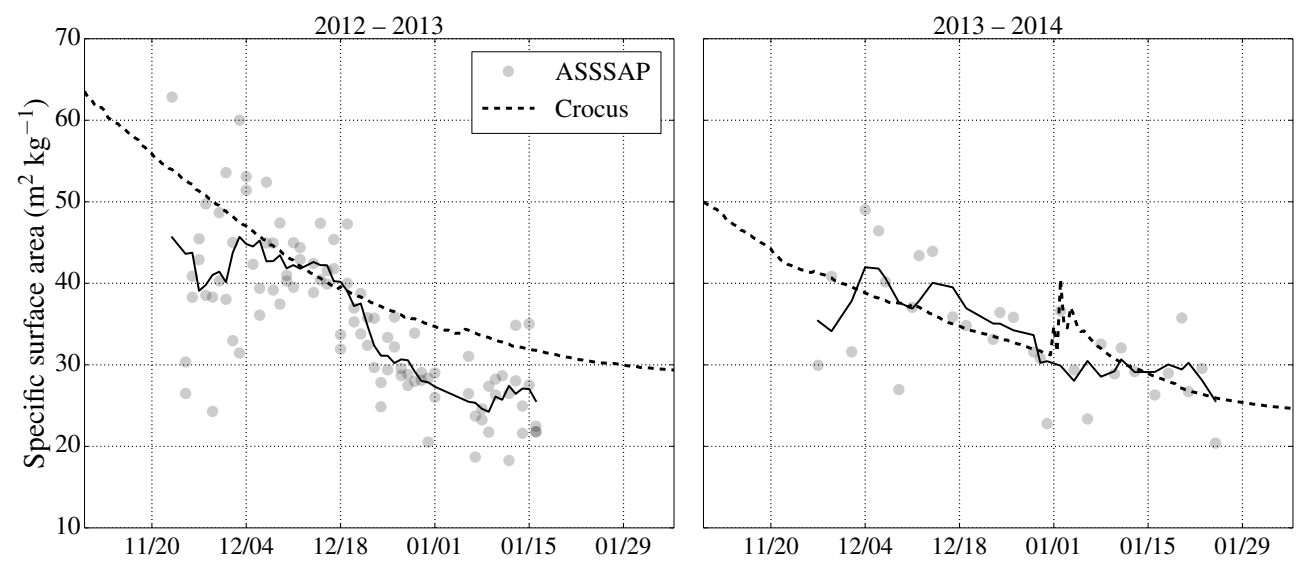

Figure 5. Evolution of SSA averaged over the top $10 \mathrm{~cm}$, deduced from vertical profiles of SSA taken with ASSSAP for the summers 2012-2013 and 2013-2014, and simulated with Crocus. The integrated value from each profile is indicated by a circle. The continuous lines correspond to the 4-day moving averages of the measurements.

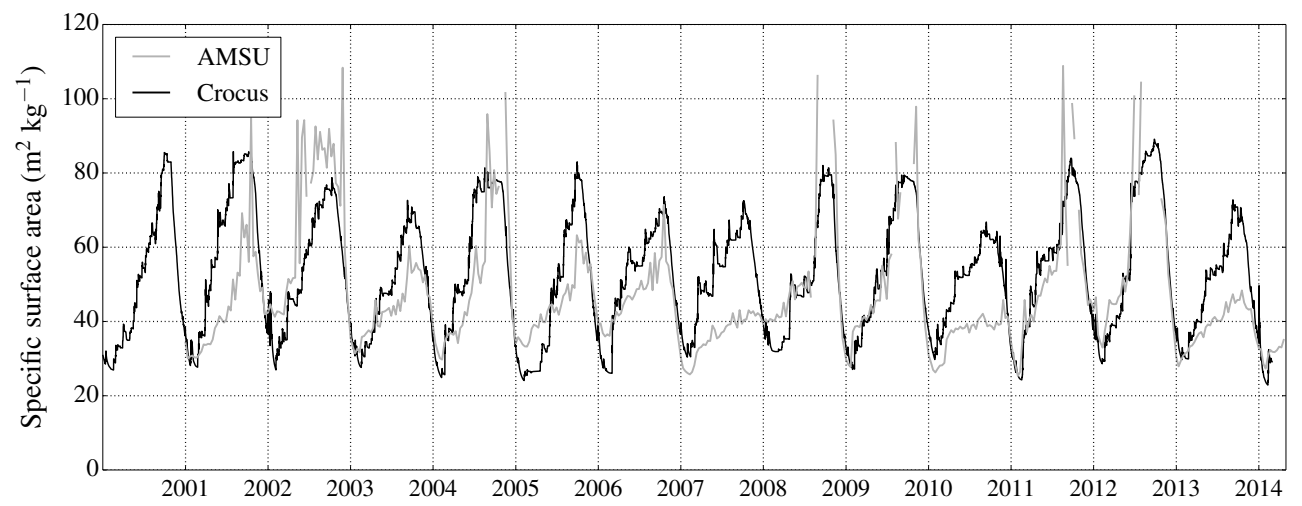

Figure 6. Comparison of SSA evolution deduced from AMSU brightness temperatures at 89 and $150 \mathrm{GHz}$ and that simulated with Crocus (top $7 \mathrm{~cm}$ ).

\subsection{Metamorphism, snowfall and wind-driven SSA variations}

During the winter period at Dome $\mathrm{C}$, defined here as the period extending from late February to mid-October when metamorphism is insignificant, snowfalls deposit onto the surface fresh snow whose detailed characteristics generally depend on weather conditions, but whose SSA is invariably high. Snow metamorphism is very limited during this period due to the prevailing extremely low temperatures. As a consequence, at the end of winter, snow properties in the layer accumulated during this period ( $\sim 6 \mathrm{~cm}$ according to Libois et al., 2014a) mainly reflect the properties of winter precipitation. In late October, as solar radiation becomes stronger and air temperature increases, snow metamorphism starts, resulting in an approximate 3-fold decrease of SSA by mid-February. The time of initiation of summer metamorphism in the Crocus simulation is very consistent with the observations, as well as the date when minimum SSA is reached. Conversely, the amplitude of the SSA decrease is more contrasted between observations and model. Supplementary simulations were thus performed to investigate what drives the amplitude of summertime metamorphism in Crocus.

The results of simulation $\mathrm{B}$, where summer precipitation was inhibited, imply that snow metamorphism only weakly depends on the total amount of precipitation during summer (Fig. 7), probably less than proposed by Picard et al. (2012). Indeed, the minimum average SSA for the topmost $7 \mathrm{~cm}$ at the end of summer simulated by Crocus, which is used to quantify the intensity of metamorphism, is on average only $6 \%$ lower in simulation B than in simulation A. This metamorphism indicator is chosen instead of using the decrease in SSA, because the latter is highly dependent on the SSA value at the end of the previous winter, a quantity that is likely to be erroneous in Crocus simulations. High SSA snow actually deposited during snowfall not only increases the overall SSA but also reduces snow metamorphism by inhibiting the positive feedback as proposed in Picard et al. (2012). To quantify the importance of this feedback, we run Crocus with a con- 


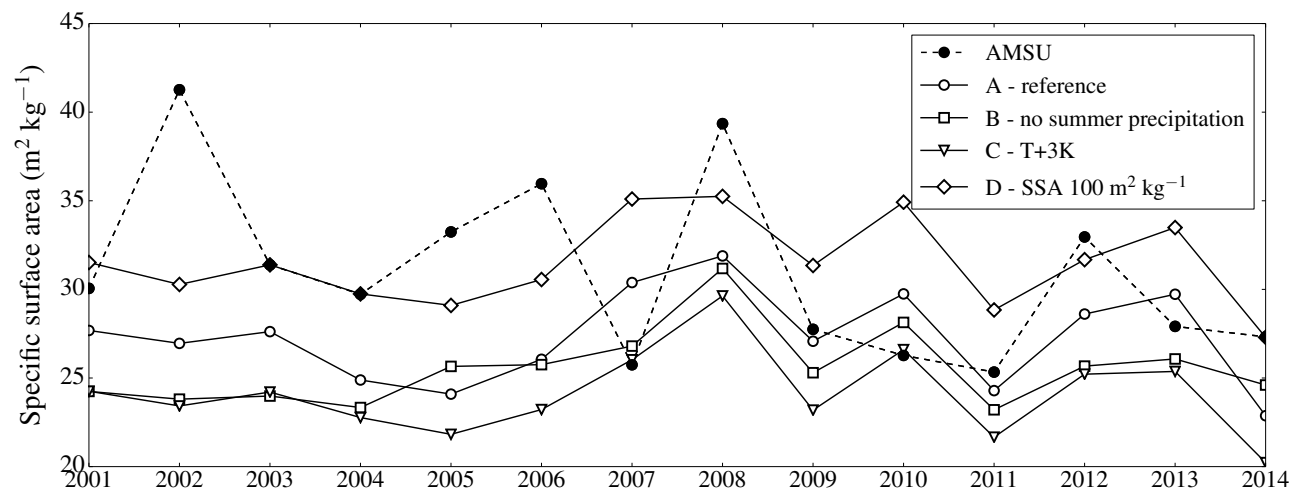

Figure 7. Minimum SSA (top $7 \mathrm{~cm}$ ) at the end of summer for AMSU estimations and Crocus simulations A, B, C and D from 2001 to 2014.

stant SSA $\left(100 \mathrm{~m}^{2} \mathrm{~kg}^{-1}\right)$ as input of the radiative transfer calculations performed with TARTES to deactivate the link between snow SSA variations and albedo, all other things being equal (simulation D). This resulted in less intense summer metamorphism (Fig. 7), with the SSA at the end of summer $15 \%$ higher than in simulation A, which is consistent with simulations using a simpler model than Crocus but with similar optical scheme, as noticed by Picard et al. (2012). This suggests that using a fine representation of snow optical properties which accounts for snow properties evolution is essential to correctly simulate SSA evolution at Dome C. The results of simulation $\mathrm{C}$, where $2 \mathrm{~m}$ air temperature was increased by $3 \mathrm{~K}$ year-long, show a $12 \%$ lower SSA at the end of summer with respect to the reference simulation. This shows that the direct effect of atmospheric warming on dry snow metamorphism is likely to remain moderate over the twenty-first century. This also highlights the primordial role of feedback loops. Overall, the sensitivity of simulated summer SSA decrease to air temperature and precipitation is relatively weak. This probably explains why the SSA decrease is less variable from one year to another in Crocus than in the observations (Fig. 7).

Although the impact of precipitation seems moderate in Crocus simulations at the seasonal scale, snowfall occurrence and amount drive Crocus-simulated SSA variations in the top $2 \mathrm{~mm}$, consistently with field observations. While the deeper layers show a seasonal SSA evolution, the surface layer mostly reflects day-to-day variations of weather conditions. To simulate the evolution of the snowpack at Dome $\mathrm{C}$, it is thus critical to know precipitation very precisely, a quantity that is difficult to obtain from reanalyses in Antarctica (Bromwich et al., 2011). In practice, ERAInterim reanalysis sometimes misses precipitation events at Dome C (Fig. 3), which explains most differences between observations and simulations. More generally, shortcomings in parameterizing the surface boundary layer on the Antarctic Plateau sometimes conduct to poorly simulated air temperature and wind profiles (Genthon et al., 2010), which probably explains part of these difference as well. Indeed, besides precipitation, surface snow at Dome $\mathrm{C}$ is also largely shaped by snow drift, which redistributes snow and controls density and SSA in the topmost centimetres (Gallée et al., 2001; Albert et al., 2004). Snow drift also generates spatial variability of snow properties close to the surface because it can accumulate fresh snow at some locations and make apparent older snow at other locations through erosion (Libois et al., 2014a), which is illustrated by the large standard deviation of surface SSA measurements in Fig. 3b. This spatial heterogeneity is difficult to simulate and makes complicated the comparison between punctual observations and simulations (Groot Zwaaftink et al., 2013). In particular, the horizontal transects of SSA used in this study are representative of approximately $1 \mathrm{~cm} \times 1 \mathrm{~m}$, which is not sufficient to capture this spatial heterogeneity, especially in the topmost millimetres of the snowpack. This might explain the discrepancies with Crocus simulation for the rapid variations of surface SSA. Conversely, the spectral albedo measurements cover an area with radius of approximately $6 \mathrm{~m}$ (Schwerdtfeger, 1976) and probe deeper into the snowpack. Hence they are more likely to be representative of the average snow SSA in the topmost $2 \mathrm{~cm}$ at Dome C, even though larger-scale spatial variability exists (e.g. Picard et al., 2014). This probably explains the success of Crocus to simulate the SSA variations derived from spectral albedo measurements (Fig. 4).

Despite a few deviations from the observations, Crocus captured well the variations of SSA in response to meteorological conditions and metamorphism at Dome C. Since metamorphism strongly depends on the temperature profile close to the surface, this suggests that Crocus successfully resolves the energy budget of the snowpack close to the surface, as already pointed out by Brun et al. (2011) and Fréville et al. (2014). It also proves that the metamorphism parameterization of Flanner and Zender (2006) is appropriate to study snow on the Antarctic Plateau, although this parameterization cannot be strictly assessed in complex conditions as encountered at Dome C. This is promising for larger-scale studies over the Antarctic Plateau and puts Crocus as an appropriate tool to investigate the spatial pattern of SSA over 

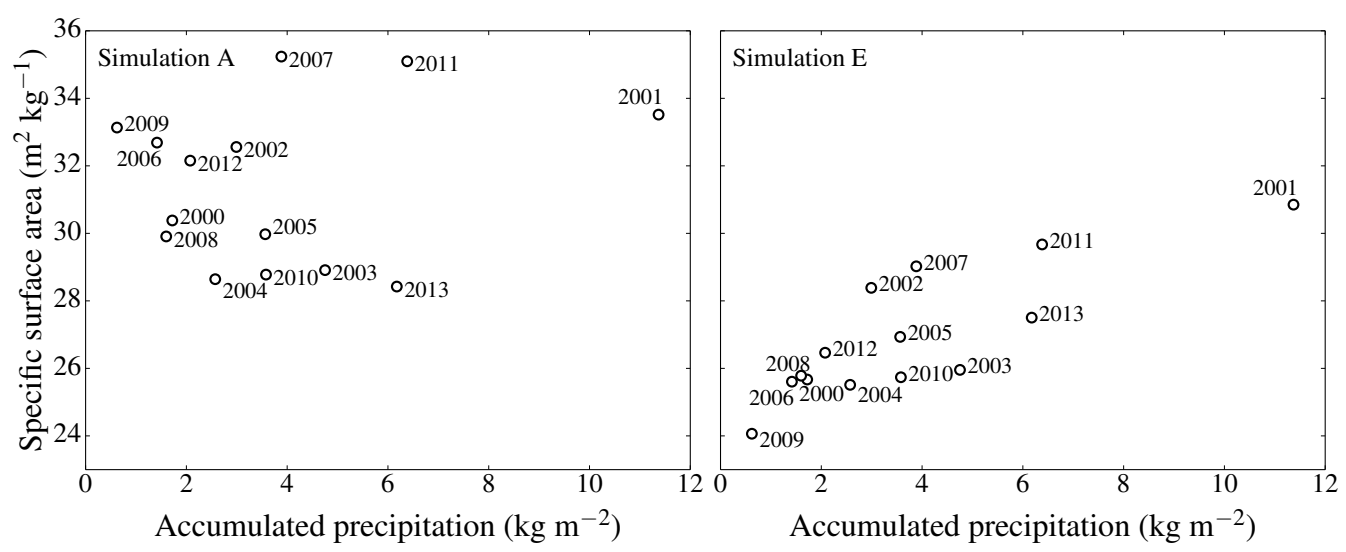

Figure 8. Minimum SSA of the topmost $7 \mathrm{~cm}$ of the snowpack simulated by Crocus for each summer (1 December-15 January) vs. accumulated precipitation during this period for simulations $\mathrm{A}$ and $\mathrm{E}$.

the Antarctic continent (Scambos et al., 2007), which probably results from the combined effects of precipitation, snow drift and metamorphism.

\subsection{Interannual variability of summer metamorphism}

The fact that Crocus poorly simulates the interannual variability of SSA summer decrease, while it proved efficient to simulate the seasonal variations, is more puzzling. Actually, the apparent intensity of the metamorphism depends both on the SSA value at the end of winter and on the rate of SSA decrease during summer, which are driven by different processes.

The differences between simulated and observed SSA at the end of winter (Fig. 6) can be attributed either to inaccuracies in ERA-Interim precipitation or to the simple treatment of fresh snow characteristics in Crocus. For instance, the large and sudden increase of SSA simulated in January 2007 (Fig. 6) results from a strong deposition event forecasted by ERA-Interim reanalysis, probably stronger than the actual event. This overestimation might result from the large horizontal scale of the reanalysis $(\sim 50 \mathrm{~km})$. As for fresh snow SSA in Crocus, it was assumed constant $\left(100 \mathrm{~m}^{2} \mathrm{~kg}^{-1}\right)$, based on our observations of summer precipitation at Dome C. In winter, due to colder conditions, the SSA of fresh snow might be higher, though, as suggested by the observations of Walden et al. (2003) who measured SSA of diamond dust up to $300 \mathrm{~m}^{2} \mathrm{~kg}^{-1}$. This highlights the need to extend the existing parameterizations of fresh snow properties developed in the Alps to polar regions.

As to the summer decrease in SSA, Picard et al. (2012) found a strong correlation between AMSU estimated metamorphism amplitude and the total amount of summer precipitation predicted by ERA-Interim (in their study, summer refers to the period of 1 December-15 January). Figure 8 shows the minimum SSA (topmost $7 \mathrm{~cm}$ ) over this summer period in terms of accumulated precipitation for the reference simulation $\mathrm{A}$ and for simulation $\mathrm{E}$, where wind remains weak throughout the year and drift events are thus inhibited. For the reference simulation, there is no significant correlation, which is contradictory to Picard et al. (2012) and to the observed influence of snowfall on the rapid variations of SSA in the present paper. On the contrary, for simulation $\mathrm{E}$ the correlation is significant $(r=0.81)$, in agreement with AMSU observations. This suggests that the impact of wind on snow SSA may be too strong in simulation A. In Crocus, snow drift increases not only surface SSA but also density through compaction, which decreases metamorphism rate (Flanner and Zender, 2006). The apparent deficiency of the reference simulation can be attributed either to an inappropriate parameterization of snow compaction and SSA increase by the wind or to an oversensitivity of snow metamorphism in Crocus which may be incorrect. This makes wind a major driver of snow metamorphism in the reference simulation and highlights the need to further understand the impact of drift events on surface snow density.

\section{Conclusions}

Crocus simulations suited to the meteorological conditions of the Antarctic Plateau were compared to in situ and satellitederived measurements of snow SSA at Dome C in order to identify the processes controlling SSA evolution on the Antarctic Plateau. The observations show rapid variations of SSA close to the surface, mainly due to precipitation and snow drift. They also confirm the existence of a seasonal cycle of SSA in the topmost $10 \mathrm{~cm}$ of the snowpack, characterized by a 2-to-3-fold decrease of SSA in summer and a slower, continuous increase in winter due to accumulation of precipitation crystals with high SSA. These variations of SSA are successfully simulated by Crocus, provided the meteorological forcing is adequate. In particular, the intensity of the summer metamorphism and the date of its initiation agree well with the observations. However, the interannual 
variability of the summer decrease in SSA is not well captured, probably because the parameterization of the effect of snow drift on snow SSA is too strong in the model. This study demonstrates that Crocus can capture the main features of snow metamorphism in the conditions of Dome C for which it was not originally developed, which is promising for extended studies of surface snow SSA and evolution at the scale of the Antarctic Plateau or the whole continent. Nevertheless, SSA is very dependent on the occurrence and intensity of precipitation events, which are known to be difficult to predict by reanalysis, highlighting the need to further improve the characterization of precipitation in this high and extremely dry region. Other physical processes not yet simulated by Crocus should also be regarded as potential progress for simulating snow properties on the Antarctic Plateau, such as the formation of hoar crystals, and the mixing of the topmost layers of the snowpack due to snow drift.

\section{Data availability}

The data used in this study are available upon request from the authors (ghislain.picard@ujf-grenoble.fr). The Crocus simulations were performed with SURFEX v7.3, adapted to Antarctic conditions. The version of Crocus incorporating the specific developments described in this article has not yet been officially released but is available upon request to crocus@meteo.fr.

Author contributions. Q. Libois, G. Picard, L. Arnaud and E. Lefebvre participated to in situ measurements at Dome C. Q. Libois developed the Antarctic parameterizations of Crocus and performed the corresponding simulations. G. Picard performed the DMRT-ML simulations. Q. Libois and G. Picard analysed satellite and field data. M. Dumont contributed to the parameterization of incident solar radiation in TARTES. M. Lafaysse implemented the model TARTES in Crocus. S. Morin helped with Crocus simulations and implemented the Antarctic parameterizations in the code. Q. Libois and G. Picard prepared the manuscript with contributions from M. Dumont, M. Lafaysse and S. Morin.

Acknowledgements. We are grateful to the anonymous reviewers and the editor for their valuable comments. LGGE is part of LabEx OSUG@2020 (ANR10 LABX56). This study was supported by the ANR program 1-JS56-005-01 MONISNOW. The authors acknowledge the French Polar Institute (IPEV) for the financial and logistic support at Concordia station in Antarctica through the CALVA-Neige and NIVO programs. We thank Eric Brun for insightful discussions about Crocus parameterizations. We are grateful to Arnaud Mialon for helping with the measurements at Dome C. The editor thanks the anonymous reviewers for their work.

Edited by: M. Schneebeli

\section{References}

Albert, M., Shuman, C., Courville, Z., Bauer, R., Fahnestock, M., and Scambos, T.: Extreme firn metamorphism: impact of decades of vapor transport on near-surface firn at a low-accumulation glazed site on the East Antarctic plateau, Ann. Glaciol., 39, 7378, doi:10.3189/172756404781814041, 2004.

Arnaud, L., Picard, G., Champollion, N., Domine, F., Gallet, J., Lefebvre, E., Fily, M., and Barnola, J.: Measurement of vertical profiles of snow specific surface area with a $1 \mathrm{~cm}$ resolution using infrared reflectance: instrument description and validation, J. Glaciol., 57, 17-29, doi:10.3189/002214311795306664, 2011. Augustin, L., Barbante, C., Barnes, P. R. F., Marc Barnola, J., Bigler, M., Castellano, E., Cattani, O., Chappellaz, J., DahlJensen, D., Delmonte, B., Dreyfus, G., Durand, G., Falourd, S., Fischer, H., Flückiger, J., Hansson, M. E., Huybrechts, P., Jugie, G., Johnsen, S. J., Jouzel, J., Kaufmann, P., Kipfstuhl, J., Lambert, F., Lipenkov, V. Y., Littot, G. C., Longinelli, A., Lorrain, R., Maggi, V., Masson-Delmotte, V., Miller, H., Mulvaney, R., Oerlemans, J., Oerter, H., Orombelli, G., Parrenin, F., Peel, D. A., Petit, J.-R., Raynaud, D., Ritz, C., Ruth, U., Schwander, J., Siegenthaler, U., Souchez, R., Stauffer, B., Peder Steffensen, J., Stenni, B., Stocker, T. F., Tabacco, I. E., Udisti, R., van de Wal, R. S. W., van den Broeke, M., Weiss, J., Wilhelms, F., Winther, J.-G., Wolff, E. W., and Zucchelli, M.: Eight glacial cycles from an Antarctic ice core, Nature, 429, 623-628, doi:10.1038/nature02599, 2004.

Bernhard, G., and Seckmeyer, G.: New entrance optics for solar spectral UV measurements, Photochem. Photobiol., 65, 923930, doi:10.1111/j.1751-1097.1997.tb07949.x, 1997.

Bindschadler, R., Choi, H., Shuman, C., and Markus, T.: Detecting and measuring new snow accumulation on ice sheets by satellite remote sensing, Remote Sens. Environ., 98, 388-402, doi:10.1016/j.rse.2005.07.014, 2005.

Box, J. E., Fettweis, X., Stroeve, J. C., Tedesco, M., Hall, D. K., and Steffen, K.: Greenland ice sheet albedo feedback: thermodynamics and atmospheric drivers, The Cryosphere, 6, 821-839, doi:10.5194/tc-6-821-2012, 2012.

Bromwich, D. H., Nicolas, J. P., and Monaghan, A. J.: An assessment of precipitation changes over Antarctica and the Southern Ocean since 1989 in contemporary global reanalyses, J. Climate, 24, 4189-4209, doi:10.1175/2011JCLI4074.1, 2011.

Brucker, L., Picard, G., and Fily, M.: Snow grain-size profiles deduced from microwave snow emissivities in Antarctica, J. Glaciol., 56, 514-526, doi:10.3189/002214310792447806, 2010.

Brun, E., Martin, E., Simon, V., Gendre, C., and Coléou, C.: An energy and mass model of snow cover suitable for operational avalanche forecasting, J. Glaciol., 35, 333-342, 1989.

Brun, E., David, P., Sudul, M., and Brunot, G.: A numerical model to simulate snow-cover stratigraphy for operational avalanche forecasting, J. Glaciol., 38, 13-22, 1992.

Brun, E., Six, D., Picard, G., Vionnet, V., Arnaud, L., Bazile, E., Boone, A., Bouchard, A., Genthon, C., Guidard, V., Le Moigne, P., Rabier, F., and Seity, Y.: Snow/atmosphere coupled simulation at Dome C, Antarctica, J. Glaciol., 57, 721-736, doi:10.3189/002214311797409794, 2011.

Carmagnola, C. M., Domine, F., Dumont, M., Wright, P., Strellis, B., Bergin, M., Dibb, J., Picard, G., Libois, Q., Arnaud, L., and Morin, S.: Snow spectral albedo at Summit, Greenland: measure- 
ments and numerical simulations based on physical and chemical properties of the snowpack, The Cryosphere, 7, 1139-1160, doi:10.5194/tc-7-1139-2013, 2013.

Carmagnola, C. M., Morin, S., Lafaysse, M., Domine, F., Lesaffre, B., Lejeune, Y., Picard, G., and Arnaud, L.: Implementation and evaluation of prognostic representations of the optical diameter of snow in the SURFEX/ISBA-Crocus detailed snowpack model, The Cryosphere, 8, 417-437, doi:10.5194/tc-8-417-2014, 2014.

Champollion, N., Picard, G., Arnaud, L., Lefebvre, E., and Fily, M.: Hoar crystal development and disappearance at Dome C, Antarctica: observation by near-infrared photography and passive microwave satellite, The Cryosphere, 7, 1247-1262, doi:10.5194/tc-7-1247-2013, 2013.

Colbeck, S. C.: Theory of metamorphism of dry snow, J. Geophys. Res., 88, 5475, doi:10.1029/JC088iC09p05475, 1983.

Dang, H., Genthon, C., and Martin, E.: Numerical modeling of snow cover over polar ice sheets, Ann. Glaciol., 25, 170-176, 1997.

Dee, D. P., Uppala, S. M., Simmons, A. J., Berrisford, P., Poli, P., Kobayashi, S., Andrae, U., Balmaseda, M. A., Balsamo, G., Bauer, P., Bechtold, P., Beljaars, A. C. M., van de Berg, L., Bidlot, J., Bormann, N., Delsol, C., Dragani, R., Fuentes, M., Geer, A. J., Haimberger, L., Healy, S. B., Hersbach, H., Hólm, E. V., Isaksen, L., Kållberg, P., Köhler, M., Matricardi, M., McNally, A. P., Monge-Sanz, B. M., Morcrette, J.-J., Park, B.K., Peubey, C., de Rosnay, P., Tavolato, C., Thépaut, J.-N., and Vitart, F.: The ERA-Interim reanalysis: configuration and performance of the data assimilation system, Q. J. Roy. Meteor. Soc., 137, 553-597, doi:10.1002/qj.828, 2011.

Domine, F., Salvatori, R., Legagneux, L., Salzano, R., Fily, M., and Casacchia, R.: Correlation between the specific surface area and the short wave infrared (SWIR) reflectance of snow, Cold Reg. Sci. Technol., 46, 60-68, doi:10.1016/j.coldregions.2006.06.002, 2006.

Domine, F., Taillandier, A.-S., Cabanes, A., Douglas, T. A., and Sturm, M.: Three examples where the specific surface area of snow increased over time, The Cryosphere, 3, 31-39, doi:10.5194/tc-3-31-2009, 2009.

Flanner, M. G. and Zender, C. S.: Linking snowpack microphysics and albedo evolution, J. Geophys. Res., 111, D12208, doi:10.1029/2005JD006834, 2006.

Frezzotti, M., Pourchet, M., Flora, O., Gandolfi, S., Gay, M., Urbini, S., Vincent, C., Becagli, S., Gragnani, R., Proposito, M., Severi, M., Traversi, R., Udisti, R., and Fily, M.: New estimations of precipitation and surface sublimation in East Antarctica from snow accumulation measurements, Clim. Dynam., 23, 803-813, doi:10.1007/s00382-004-0462-5, 2004.

Fréville, H., Brun, E., Picard, G., Tatarinova, N., Arnaud, L., Lanconelli, C., Reijmer, C., and van den Broeke, M.: Using MODIS land surface temperatures and the Crocus snow model to understand the warm bias of ERA-Interim reanalyses at the surface in Antarctica, The Cryosphere, 8, 1361-1373, doi:10.5194/tc-81361-2014, 2014.

Fujita, S., Okuyama, J., Hori, A., and Hondoh, T.: Metamorphism of stratified firn at Dome Fuji, Antarctica: a mechanism for local insolation modulation of gas transport conditions during bubble close off, J. Geophys. Res., 114, F03023, doi:10.1029/2008JF001143, 2009.

Gallet, J.-C., Domine, F., Savarino, J., Dumont, M., and Brun, E.: The growth of sublimation crystals and surface hoar on the Antarctic plateau, The Cryosphere, 8, 1205-1215, doi:10.5194/tc-8-1205-2014, 2014.

Gallée, H., Guyomarc'h, G., and Brun, E.: Impact of snow drift on the Antarctic ice sheet surface mass balance: possible sensitivity to snow-surface properties, Bound.-Lay. Meteorol., 99, 1-19, 2001.

Gardner, A. S. and Sharp, M. J.: A review of snow and ice albedo and the development of a new physically based broadband albedo parameterization, J. Geophys. Res.-Earth, 115, 01009, doi:10.1029/2009JF001444, 2010.

Genthon, C., Town, M. S., Six, D., Favier, V., Argentini, S., and Pellegrini, A.: Meteorological atmospheric boundary layer measurements and ECMWF analyses during summer at Dome C, Antarctica, J. Geophys. Res., 115, D05104, doi:10.1029/2009JD012741, 2010.

Genthon, C., Six, D., Gallée, H., Grigioni, P., and Pellegrini, A.: Two years of atmospheric boundary layer observations on a 45-m tower at Dome C on the Antarctic plateau, J. Geophys. Res.-Atmos., 118, D05104, doi:10.1002/jgrd.50128, 2013.

Gow, A. J.: On the accumulation and seasonal stratification of snow at the South Pole, J. Glaciol., 5, 467-477, 1965.

Grenfell, T. C., Warren, S. G., and Mullen, P. C.: Reflection of solar radiation by the Antarctic snow surface at ultraviolet, visible, and near-infrared wavelengths, J. Geophys. Res., 99, 18669-18684, doi:10.1029/94JD01484, 1994.

Groot Zwaaftink, C. D., Cagnati, A., Crepaz, A., Fierz, C., Macelloni, G., Valt, M., and Lehning, M.: Event-driven deposition of snow on the Antarctic Plateau: analyzing field measurements with SNOWPACK, The Cryosphere, 7, 333-347, doi:10.5194/tc7-333-2013, 2013.

Guyomarc'h, G., and Mérindol, L.: Validation of an application for forecasting blowing snow, Ann. Glaciol., 26, 138-143, 1998.

Jin, Z., Charlock, T. P., Yang, P., Xie, Y., and Miller, W.: Snow optical properties for different particle shapes with application to snow grain size retrieval and MODIS/CERES radiance comparison over Antarctica, Remote Sens. Environ., 112, 3563-3581, doi:10.1016/j.rse.2008.04.011, 2008.

Krinner, G., Magand, O., Simmonds, I., Genthon, C., and Dufresne, J. L.: Simulated Antarctic precipitation and surface mass balance at the end of the twentieth and twenty-first centuries, Clim. Dynam., 28, 215-230, doi:10.1007/s00382-0060177-x, 2006.

Kuhn, M., Kundla, L. S., and Stroschein, L. A.: The radiation budget at Plateau Station, Antarctica, 1966-1967, in: Antarctic Research Series, vol. 25, edited by: Riordan, A. J., Riordan, A., Riordan, A. J., Weller, G., Lettau, H. H., Lettau, H., Stroschein, L. A., Kundla, L. S., Stroschein, L. A., Kuhn, M., Dalrymple, P. C., Schwerdtfeger, P., Lile, R. C., and Radok, U., American Geophysical Union, Washington, DC, 41-73, 1977.

Kuipers Munneke, P., Reijmer, C. H., van den Broeke, M. R., König-Langlo, G., Stammes, P., and Knap, W. H.: Analysis of clear-sky Antarctic snow albedo using observations and radiative transfer modeling, J. Geophys. Res., 113, D17118, doi:10.1029/2007JD009653, 2008.

Lacroix, P., Legresy, B., Remy, F., Blarel, F., Picard, G., and Brucker, L.: Rapid change of snow surface properties at Vostok, East Antarctica, revealed by altimetry and radiometry, Remote Sens. Environ., 113, 2633-2641, doi:10.1016/j.rse.2009.07.019, 2009. 
Libois, Q., Picard, G., France, J. L., Arnaud, L., Dumont, M., Carmagnola, C. M., and King, M. D.: Influence of grain shape on light penetration in snow, The Cryosphere, 7, 1803-1818, doi:10.5194/tc-7-1803-2013, 2013.

Libois, Q., Picard, G., Arnaud, L., Morin, S., and Brun, E.: Modeling the impact of snow drift on the decameter-scale variability of snow properties on the Antarctic Plateau, J. Geophys. Res.Atmos., 119, 11662-11681, doi:10.1002/2014JD022361, 2014a.

Libois, Q., Picard, G., Dumont, M., Arnaud, L., Sergent, C., Pougatch, E., Sudul, M., and Vial, D.: Experimental determination of the absorption enhancement parameter of snow, J. Glaciol., 60, 714-724, doi:10.3189/2014JoG14J015, 2014 b.

Loeb, N. G.: In-flight calibration of NOAA AVHRR visible and near-IR bands over Greenland and Antarctica, Int. J. Remote Sens., 18, 477-490, doi:10.1080/014311697218908, 1997.

Löwe, H., Riche, F., and Schneebeli, M.: A general treatment of snow microstructure exemplified by an improved relation for thermal conductivity, The Cryosphere, 7, 1473-1480, doi:10.5194/tc-7-1473-2013, 2013.

Marbouty, D.: An experimental study of temperature-gradient metamorphism, J. Glaciol., 26, 303-312, 1980.

Mary, A., Dumont, M., Dedieu, J.-P., Durand, Y., Sirguey, P., Milhem, H., Mestre, O., Negi, H. S., Kokhanovsky, A. A., Lafaysse, M., and Morin, S.: Intercomparison of retrieval algorithms for the specific surface area of snow from near-infrared satellite data in mountainous terrain, and comparison with the output of a semi-distributed snowpack model, The Cryosphere, 7, 741-761, doi:10.5194/tc-7-741-2013, 2013.

Negi, H. S. and Kokhanovsky, A.: Retrieval of snow albedo and grain size using reflectance measurements in Himalayan basin, The Cryosphere, 5, 203-217, doi:10.5194/tc-5-203-2011, 2011.

Oleson, K. W., Lawrence, D. M., Gordon, B., Flanner, M. G., Kluzek, E., Peter, J., Levis, S., Swenson, S. C., Thornton, E., and Feddema, J.: Technical Description of Version 4.0 of the Community Land Model (CLM), National Center for Atmospheric Research, Boulder, CO, USA, 2010.

Picard, G., Brucker, L., Fily, M., Gallée, H., and Krinner, G.: Modeling time series of microwave brightness temperature in Antarctica, J. Glaciol., 55, 537-551, doi:10.3189/002214309788816678, 2009.

Picard, G., Domine, F., Krinner, G., Arnaud, L., and Lefebvre, E.: Inhibition of the positive snow-albedo feedback by precipitation in interior Antarctica, Nature Clim. Change, 2, 795-798, doi:10.1038/nclimate1590, 2012.

Picard, G., Brucker, L., Roy, A., Dupont, F., Fily, M., Royer, A., and Harlow, C.: Simulation of the microwave emission of multilayered snowpacks using the Dense Media Radiative transfer theory: the DMRT-ML model, Geosci. Model Dev., 6, 1061-1078, doi:10.5194/gmd-6-1061-2013, 2013.

Picard, G., Royer, A., Arnaud, L., and Fily, M.: Influence of meter-scale wind-formed features on the variability of the microwave brightness temperature around Dome C in Antarctica, The Cryosphere, 8, 1105-1119, doi:10.5194/tc-8-1105-2014, 2014.

Ricchiazzi, P., Yang, S., Gautier, C., and Sowle, D.: SBDART: A research and teaching software tool for planeparallel radiative transfer in the earth's atmosphere, B. Am. Meteorol. Soc., 79, 2101-2114, doi:10.1175/15200477(1998)079<2101:SARATS>2.0.CO;2, 1998.
Scambos, T., Haran, T., Fahnestock, M., Painter, T., and Bohlander, J.: MODIS-based Mosaic of Antarctica (MOA) data sets: continent-wide surface morphology and snow grain size, Remote Sens. Environ., 111, 242-257, doi:10.1016/j.rse.2006.12.020, 2007.

Schwerdtfeger, P.: Physical principles of micro-meteorological measurements, 113 pp., Elsevier Sci., New York, 1976.

Six, D., Fily, M., Alvain, S., Henry, P., and Benoist, J.-P.: Surface characterisation of the Dome Concordia area (Antarctica) as a potential satellite calibration site, using Spot 4/Vegetation instrument, Remote Sens. Environ., 89, 83-94, doi:10.1016/j.rse.2003.10.006, 2004.

Sturm, M., Holmgren, J., König, M., and Morris, K.: The thermal conductivity of seasonal snow, J. Glaciol., 43, 26-41, 1997.

Surdyk, S.: Using microwave brightness temperature to detect short-term surface air temperature changes in Antarctica: an analytical approach, Remote Sens. Environ., 80, 256-271, doi:10.1016/S0034-4257(01)00308-X, 2002.

Taillandier, A.-S., Domine, F., Simpson, W. R., Sturm, M., and Douglas, T. A.: Rate of decrease of the specific surface area of dry snow: Isothermal and temperature gradient conditions, J. Geophys. Res.-Earth, 112, 03003, doi:10.1029/2006JF000514, 2007.

Town, M. S., Waddington, E. D., Walden, V. P., and Warren, S. G.: Temperatures, heating rates and vapour pressures in near-surface snow at the South Pole, J. Glaciol., 54, 487-498, doi:10.3189/002214308785837075, 2008.

Tremblin, P., Minier, V., Schneider, N., Durand, G. A., Ashley, M. C. B., Lawrence, J. S., Luong-Van, D. M., Storey, J. W. V., Durand, G. A., Reinert, Y., Veyssiere, C., Walter, C., Ade, P., Calisse, P. G., Challita, Z., Fossat, E., Sabbatini, L., Pellegrini, A., Ricaud, P., and Urban, J.: Site testing for submillimetre astronomy at Dome C, Antarctica, Astron. Astrophys., 535, A112, doi:10.1051/0004-6361/201117345, 2011.

Van As, D., Van Den Broeke, M., and Van De Wal, R.: Daily cycle of the surface layer and energy balance on the high Antarctic Plateau, Antarct. Sci., 17, 121-133, 2005.

van den Broeke, M.: Surface radiation balance in Antarctica as measured with automatic weather stations, J. Geophys. Res., 109, D09103, doi:10.1029/2003JD004394, 2004.

van Oldenborgh, G., Collins, M., Arblaster, J., Christensen, J., Marotzke, J., Power, S., Rummukainen, M., and Zhou, T.: IPCC, 2013: Annex I: atlas of global and regional climate projections, in: Climate Change 2013: The Physical Science Basis. Contribution of Working Group I to the Fifth Assessment Report of the Intergovernmental Panel on Climate Change, 1311-1393, Cambridge University Press, Cambridge, UK and New York, NY, 2013.

Vionnet, V., Brun, E., Morin, S., Boone, A., Faroux, S., Le Moigne, P., Martin, E., and Willemet, J.-M.: The detailed snowpack scheme Crocus and its implementation in SURFEX v7.2, Geosci. Model Dev., 5, 773-791, doi:10.5194/gmd-5-773-2012, 2012.

Walden, V. P., Warren, S. G., and Tuttle, E.: Atmospheric ice crystals over the Antarctic Plateau in winter, J. Appl. Meteorol., 42, 1391-1405, doi:10.1175/15200450(2003)042<1391:AICOTA>2.0.CO;2, 2003.

Wang, X. and Zender, C. S.: Arctic and Antarctic diurnal and seasonal variations of snow albedo from multiyear Baseline Surface Radiation Network measurements, J. Geophys. Res.-Earth, 116, 03008, doi:10.1029/2010JF001864, 2011. 
Warren, S. G.: Optical properties of snow, Rev. Geophys., 20, 67, doi:10.1029/RG020i001p00067, 1982.

Warren, S. G. and Brandt, R. E.: Optical constants of ice from the ultraviolet to the microwave: a revised compilation, J. Geophys. Res., 113, D14220, doi:10.1029/2007JD009744, 2008.

Warren, S. G. and Wiscombe, W. J.: A model for the spectral albedo of snow, II: snow containing atmospheric aerosols, J. Atmos. Sci., 37, 2734-2745, doi:10.1175/15200469(1980)037<2734:AMFTSA>2.0.CO;2, 1980.
Warren, S. G., Brandt, R. E., and Grenfell, T. C.: Visible and near-ultraviolet absorption spectrum of ice from transmission of solar radiation into snow, Appl. Optics, 45, 5320, doi:10.1364/AO.45.005320, 2006.

Zege, E., Katsev, I., Malinka, A., Prikhach, A., and Polonsky, I.: New algorithm to retrieve the effective snow grain size and pollution amount from satellite data, Ann. Glaciol., 49, 139-144, doi:10.3189/172756408787815004, 2008. 